Illinois State University

ISU ReD: Research and eData

Theses and Dissertations

3-8-2021

\title{
Barriers To Physical Activity In University Students Referred To An Exercise Is Medicine On Campus Program
}

Alexander Michael DiSerio

Illinois State University, alexander.diserio@yahoo.com

Follow this and additional works at: https://ir.library.illinoisstate.edu/etd

Part of the Kinesiology Commons

\section{Recommended Citation}

DiSerio, Alexander Michael, "Barriers To Physical Activity In University Students Referred To An Exercise Is Medicine On Campus Program" (2021). Theses and Dissertations. 1361.

https://ir.library.illinoisstate.edu/etd/1361

This Thesis is brought to you for free and open access by ISU ReD: Research and eData. It has been accepted for inclusion in Theses and Dissertations by an authorized administrator of ISU ReD: Research and eData. For more information, please contact ISUReD@ilstu.edu. 


\section{BARRIERS TO PHYSICAL ACTIVITY IN UNIVERSITY STUDENTS REFERRED TO AN \\ EXERCISE IS MEDICINE ON CAMPUS PROGRAM}

\section{ALEXANDER M. DISERIO}

24 Pages

PURPOSE: The purpose was to describe barriers to being physically active based on reason for referral, gender identity, and incoming stage of change (SOC) for physical activity (PA) in university students referred to an Exercise is Medicine on Campus (EIMOC) program. METHODS: Students ( $21.9 \pm 4.1$ years of age) referred by university health and counseling services completed a 20-item questionnaire, which included the "Barriers to Being Active" quiz, an assessment of SOC (e.g., precontemplation), and students' self-reported gender. Reason for referral (RFR), which was provided by a health practitioner, was categorized as Obesity, Anxiety/Depression, General PA, Unspecified or Other. RESULTS: A barrier mean score over 5 is considered an important barrier. Overall, a Lack of Willpower was the most highly rated barrier followed by Lack of Energy. A series of MANOVAs revealed non-significant differences in the set of barriers across the three grouping variables. However, follow-up ANOVAs showed that those classified as being at the Pre-preparation stage (identified as contemplation or precontemplation) were higher on Lack of Willpower relative to those at Action or Maintenance, and higher than Action on Lack of Skill. Results also showed that those identifying as male reported a higher Lack of Skill compared to those identifying as female. CONCLUSION: Identifying client barriers is essential for promoting participation and adherence to PA for EIMOC. Lack of Energy and Lack of Willpower seem to be common, important barriers regardless of gender identity, reason for referral, or SOC.

KEYWORDS: Barriers, Exercise Is Medicine On Campus, Physical Activity, Students, Stage of Change, University 


\title{
BARRIERS TO PHYSICAL ACTIVITY IN UNIVERSITY STUDENTS REFERRED TO AN EXERCISE IS MEDICINE ON CAMPUS PROGRAM
}

\author{
ALEXANDER M. DISERIO
}

A Thesis Submitted in Partial Fulfillment of the Requirements for the Degree of

\section{MASTER OF SCIENCE}

School of Kinesiology and Recreation

ILLINOIS STATE UNIVERSITY 
(C) 2021 Alexander M. DiSerio 


\section{BARRIERS TO PHYSICAL ACTIVITY IN UNIVERSITY STUDENTS REFERRED TO AN EXERCISE IS MEDICINE ON CAMPUS PROGRAM}

ALEXANDER M. DISERIO

COMMITTEE MEMBERS:

Kristen M. Lagally, Chair

Anthony J. Amorose

Anna Rinaldi-Miles 


\section{ACKNOWLEDGMENTS}

I would like to express my sincere gratitude and appreciation for my head thesis chair, Dr. Kirsten M. Lagally, who helped insure all the proper steps in the research and writing process when creating this thesis exceeded all expectations set forth. Thank you, Dr. Lagally, for being supportive and encouraging during the entire thesis process. I would also like to express a thank you to my other committee chair members, Dr. Anthony J. Amorose and Dr. Anna Rinaldi-Miles for all of the directional and informational input during the thesis process, especially for their efforts in pushing myself in the direction we decided to take on with this research. All of this would not be possible without all of your bright minds, patience, and hard work.

A.M.D. 


\section{CONTENTS}

Page

ACKNOWLEDGMENTS

$\begin{array}{ll}\text { TABLES } & \text { iii }\end{array}$

CHAPTER I: INTRODUCTION 1

CHAPTER II: METHODS

Participant Data

Data Grouping $\quad 5$

Questionnaire Data Collection $\quad 6$

$\begin{array}{ll}\text { Statistical Analysis } & 8\end{array}$

CHAPTER III: RESULTS 9

CHAPTER IV: DISCUSSION

$\begin{array}{ll}\text { Strategies For Overcoming Barriers } & 17\end{array}$

$\begin{array}{ll}\text { Study Limitations } & 18\end{array}$

$\begin{array}{ll}\text { Summary } & 18\end{array}$

$\begin{array}{lr}\text { REFERENCES } & 20\end{array}$ 


\section{TABLES}

Table

Page

1. Participant Characteristics 5

2. Participant Barriers - Means + Standard Deviation 10 


\section{CHAPTER I: INTRODUCTION}

Since 2007, the American College of Sports Medicine (ACSM) and the American Medical Association (AMA) co-launched Exercise is Medicine ${ }^{\circledR}(\mathrm{EIM})$ - a health initiative that has since been coordinated solely by ACSM (37). The initiative asks healthcare providers to assess physical activity (PA) as a vital sign, similar to when a visit to a health practitioner includes measurements of vital signs such as blood pressure and heart rate. As PA levels gain more traction as a vital sign, EIM hopes to make PA a standard in clinical care and promote connections between health care and evidence-based PA resources. Numerous studies have demonstrated that individuals who are habitually physically active live longer, are healthier, and have better-quality lives (32). These studies also suggest that as a result of becoming more active, individuals with existing diseases or co-morbidities also show progress in either completely eliminating these diseases or reducing the associated negative effects such as hypertension, diabetes, and other chronic diseases $(4,24,33)$.

Exercise Is Medicine On Campus (EIMOC) is a subdivision of the EIM initiative, and calls upon universities to carry out the EIM mission (3). Colleges and universities provide an optimal setting for coordination of health care and PA resources because many campuses already house health services, recreation centers, and kinesiology programs. Additionally, college students are an optimal target population due to their recent move into adulthood, as well as the many changes associated with beginning a college career. College students can face a number of challenges that can lead to reductions in PA $(14,32)$, such as fewer sport and PA opportunities compared to high school, increased time, money and social pressures, unfamiliarity with university recreation resources and programs, and lack of motivation and knowledge regarding 
self-led exercise programs. Previous research indicates that less than $40 \%$ of university students are achieving recommended PA levels $(9,36)$. As such, providing structured PA opportunities could help students overcome some of these barriers, as well as counteract the stress, anxiety, weight gain, and reductions in overall health that can be associated with university life and low PA levels $(18,20,21,26,29,34)$.

As part of the EIMOC initiative, the ACSM encourages student referrals from university health services to university PA resources to promote increasing PA levels and meeting minimal PA recommendations. Referrals may be made for any number of reasons - not only if a student has low PA levels, but also in situations where PA may benefit existing health conditions, like obesity, hypertension or anxiety. Regardless of the reason for referral (RFR), the goal is to increase PA levels, so helping students to identify, overcome, and move past barriers is important to keep them engaged in PA during and after college. Identifying barriers at the onset of an exercise intervention can provide useful information for exercise programming and prescription $(13,15,25)$. For instance, if a client has a Lack of Skill, the exercise professional can focus on building knowledge and skill as part of the training program. If a client lacks resources, an exercise professional may provide PA options that require minimal equipment. Previous research in university students has suggested a number of significant barriers to PA, including time constraints (32) Lack of Motivation (2,19), and Lack of Self-efficacy (12). Sevil et al. (32) noted that university students who were not currently active were found to have more barriers to PA than those who were already physically active. Additional findings from research on barriers in university students include that women may have different barriers than men, and that external barrier (e.g. lack of equipment or Lack of Social Support for PA) seem to be more significant in 
university students than internal barriers (e.g. no energy, no motivation) $(5,6)$.

The students in these previous studies were apparently-healthy adults, whose barriers to PA may differ from students referred to a PA program with existing health conditions. Identifying barriers in this population may be of particular importance given that PA levels decrease around the time of diagnosis of a health condition (17). Previous research in adults with diabetes (17) indicated that, like the results from the general university student population, external barriers were more significant than internal barriers. On the other hand, obese adults (13) and adults with anxiety disorders (25) indicated that internal barriers such as "exercise is hard work for me" or "lack of willpower" were more important than external barriers.

The Transtheoretical Model of Behavior Change (TTM) has been utilized repeatedly in research pertaining to PA and has been viewed as being one of the most effective models to look at behavior change. The model suggests that change occurs gradually and involves progression through several stages (2). The Stages of Change (SOC) within the TTM can be categorized into five stages: Pre-contemplation, Contemplation, Preparation, Action, and Maintenance. Those categorized in the Pre-preparation SOC are individuals who are either have no intentions of making a behavior change (Pre-contemplation), or intend to make a PA behavior change within the next 6 months (Contemplation) $(3,32)$. Those in the Preparation SOC are individuals are currently participating in PA but not on a regular basis or not meeting American College of Sports Medicine (ACSM)recommendations for PA (3,32). Those in the Action SOC are currently exercising at the ACSM recommended amount of PA within a 6 month period $(3,32)$ and finally, those who are in the Maintenance SOC are individuals who are engaging in the recommended amount of PA for over 6 months $(3,32)$. According to Sevil et al., where individuals land on the 
SOC model and how they progress through each stage may be related to the barriers identified as being obstacles for regular PA (32).

Given the minimal evidence available on barriers to PA in university students referred to an exercise program on campus, the purpose of this study was to examine barriers to PA in college students referred to an EIMOC program overall, as well as when grouped by gender identity, reason for referral and SOC for PA. It was hypothesized that individuals from different gender identity, SOC and RFR groups would identify different significant barriers for PA. 


\section{CHAPTER II: METHODS}

\section{Participant Data}

Participants were 114 undergraduate and graduate student volunteers $(21.9 \pm 4.1$ years of age) referred to an EIMOC program by the University's Student Health Services (SHS) or Student Counseling Services (SCS) between the years of 2016 and 2020. Participant characteristics are shown in Table 1. Gender identity and SOC for PA were self-reported. Height and weight are not routinely gathered by EIMOC staff and so are not included here. Three participants did not identify their SOC and in 28 cases, an RFR was not provided. Only one student identified as being in precontemplation, and so was combined with those in the contemplation group to make one SOC group, called Pre-preparation.

Table 1 Participant Characteristics

\begin{tabular}{|l|l|l|}
\hline Participant Characteristics (N = 114) & n & Percentage \\
\hline Identified as Female & $\mathbf{8 7}$ & $\mathbf{7 6 . 3 \%}$ \\
\hline Identified as Male & $\mathbf{2 7}$ & $\mathbf{2 3 . 7 \%}$ \\
\hline RFR: Obesity & $\mathbf{2 0}$ & $\mathbf{1 7 . 5 \%}$ \\
\hline RFR: Anxiety/Depression & $\mathbf{2 6}$ & $\mathbf{2 2 . 8 \%}$ \\
\hline RFR: General PA & $\mathbf{1 7}$ & $\mathbf{1 4 . 9 \%}$ \\
\hline RFR: Other Reason for Referral & $\mathbf{2 3}$ & $\mathbf{2 0 . 2 \%}$ \\
\hline RFR: Unspecified & $\mathbf{2 8}$ & $\mathbf{2 4 . 6 \%}$ \\
\hline SOC: Pre-preparation & $\mathbf{2 3}$ & $\mathbf{2 0 . 2 \%}$ \\
\hline SOC: Preparation & $\mathbf{6 2}$ & $\mathbf{5 4 . 4 \%}$ \\
\hline SOC: Action & $\mathbf{1 2}$ & $\mathbf{1 0 . 5 \%}$ \\
\hline SOC: Maintenance & $\mathbf{1 4}$ & $\mathbf{1 2 . 3 \%}$ \\
\hline
\end{tabular}

RFR $=$ reason for referral, SOC $=$ stage of change for physical activity, Pre-preparation $=$ combined category including precontemplators and contemplators

\section{Data Grouping}

Participants were grouped based gender identity, SOC for PA, and on reason for referral (RFR) provided by SHS or SCS if the student provided permission to release this information. 
The most common RFR were Obesity (including abnormal weight gain and BMI), Anxiety/Depression, and General PA (including those with low PA levels and individuals needing exercise counseling or assistance). An "other reason for referral" category was created to group the remaining individuals who had been provided with an RFR, but whose RFR was in a group with fewer than 10 individuals referred for that reason. This group included RFR of disordered eating $(\mathrm{n}=7)$, diabetes/pre-diabetes $(\mathrm{n}=6)$, hypertension/pre-hypertension $(\mathrm{n}=4)$, or high cholesterol ( $\mathrm{n}=2)$. Participants without an RFR were put into an RFR group labeled "unspecified" (n=28).

\section{Questionnaire Data Collection}

Upon referral to the EIMOC program, each participant was asked to complete an intake questionnaire. The questionnaire asked participants to indicate their current PA levels (using the Stage of Change model), gender identity, and barriers for PA. Barriers were assessed using the "Barriers to Being Active" quiz (https://www.cdc.gov/diabetes/ndep/pdfs/toolkits/road-tohealth/road-to-health-barriers-quiz.pdf). This quiz includes 21 items grouped into seven categories of barriers, including Lack of Time, Social Influence, Lack of Energy, Lack of Willpower, Fear of Injury, Lack of Skill, and Lack of Resources. There are three questions on the quiz associated with each category of barriers, and each question has a possible response of Very Likely (a score of 3) to Very Unlikely (a score of 0). Once complete, the quiz is scored by summing the selected numbers for each of the three questions in each barrier category. As such, the highest score for any given category would be "9", if the participant responded with "Very Likely" to each of the three related questions. A score of 5 or above in any category shows that this is a significant barrier to PA for that individual. SOC for PA was assessed using the SOC 
model developed by Prochaska and DiClemente (27). The stages include traditionally include Precontemplation, Contemplation, Preparation, Action, Maintenance and Relapse. For this study, students in the precontemplation and contemplation SOC were combined into a single category called "Pre-preparation" because only one student identified as being in the precontemplation stage. Participants were provided with the following instructions: PA to be regular it must be done for $\mathbf{3 0}$ minutes (or more) per day and be done at least $\mathbf{5}$ days per week. For example, you could take three 10-minute brisk walks or ride a bicycle for 30 minutes. PA includes such activities as walking briskly, biking, swimming, line dancing, and aerobic classes or any other activities where the exertion is similar to these activities. Your heart rate and/or breathing rate should increase, but there is no need to exhaust yourself. Precontemplators are those who are not currently exercising and do not plan to in the next 6 months. Contemplators are those who are not currently exercising and do plan to in the next 6 months. Those in the Preparation stage have been currently exercising within 6 months, but not at the recommended amount or on a regular basis. Those in the Action stage are currently exercising at the recommended amount on a regular basis within 6 months while those who are in the Maintenance stage are currently exercising at the recommended amount on a regular basis beyond 6 months.

The University Institutional review board provided approval for this study. Questionnaire data were downloaded from Qualtrics into SPSS, which was used to calculate frequencies and perform statistical analyses. RFR data were added into the SPSS database by hand. Any participant not providing consent for data to be used for research purposes were removed from the database. 


\section{Statistical Analyses}

Analyses were completed using SPSS version 26.0. Frequencies, means and standard deviations were calculated. A series of MANOVAs were performed to examine potential differences in the set of barriers across the three grouping variables (Gender, SOC, RFR) Follow-up, exploratory ANOVAs were performed. Alpha was set at 0.05 . 


\section{CHAPTER III: RESULTS}

Means and standard deviations for barriers for all participants (ALL), and by grouping variables, are provided in Table 2. Overall, a Lack of Willpower (7.2) was the most highly rated barrier followed by Lack of Energy (5.6). These were the only two barriers with mean scores above 5, which is considered a significant barrier. The mean score for the barrier of Social Influence (4.9) approached a 5 for ALL. That pattern was consistent when participants were grouped by reason for referral, with all RFR groups indicating Lack of Willpower and Lack of Energy were significant barriers (>5). Means for the barrier of Social Influence for the RFR groups of obesity (5.1), anxiety/depression (5.0), and general PA (5.0) were also at or above a 5.

The same pattern was found when participants were grouped by gender identity and by SOC, with Lack of Willpower and Lack of Energy being significant barriers. Those identifying as male reported Social Influence as a major barrier above 5 (5.4), whereas the mean for those identifying as female was 4.7. Within the SOC groups, those who were in the Pre-preparation stage were the only SOC group to report Social Influence as a major barrier (5.5) (see table 2).

A series of MANOVAs revealed non-significant differences in the set of barriers across the three grouping variables (Gender Identity, RFR, and SOC). Exploratory follow-up ANOVAs showed that those classified as being at the Pre-preparation SOC were higher on the Lack of Willpower barrier relative to those at Action or Maintenance, and higher than Action on the Lack of Skill barrier. Results also showed that those identifying as male scored more highly on Lack of Skill compared to those identifying as female. 
Table 2 Participant Barriers -Means \pm Standard Deviation

\begin{tabular}{|c|c|c|c|c|c|c|c|}
\hline Group & $\frac{\text { Lack of }}{\underline{\text { Time }}}$ & $\begin{array}{l}\text { Social } \\
\text { Influence }\end{array}$ & $\frac{\text { Lack of }}{\text { Energy }}$ & $\begin{array}{l}\text { Lack of } \\
\text { Willpower }\end{array}$ & $\frac{\text { Fear of }}{\text { Injury }}$ & $\frac{\text { Lack of }}{\underline{\text { Skill }}}$ & $\begin{array}{r}\text { Lack of } \\
\text { Resources }\end{array}$ \\
\hline $\operatorname{ALL}(n=114)$ & $4.3( \pm 2.5)$ & $4.9( \pm 2.2)$ & $5.6( \pm 2.6)$ & $7.2( \pm 2.1)$ & $1.2( \pm 1.7)$ & $3.0( \pm 2.5)$ & $2.0( \pm 1.9)$ \\
\hline Identified as Female $(\mathrm{n}=87)$ & $4.4( \pm 2.6)$ & $4.7( \pm 2.1)$ & $5.8( \pm 2.7)$ & $7.0(+2.3)$ & $1.1( \pm 1.6)$ & $2.7( \pm 2.4)$ & $1.9(+1.9)$ \\
\hline Identified as Male $(\mathrm{n}=27)$ & $4.0(+2.1)$ & $5.4( \pm 2.3)$ & $5.0( \pm 2.4)$ & $7.9( \pm 1.3)$ & $1.8(+2.1)$ & $3.9( \pm 2.7)$ & $2.5( \pm 1.9)$ \\
\hline RFR: Obesity $(n=20)$ & $4.3( \pm 3.0)$ & $5.2( \pm 2.1)$ & $5.1( \pm 3.3)$ & $6.5( \pm 2.8)$ & $1.0( \pm 1.3)$ & $2.6( \pm 2.5)$ & $1.8( \pm 1.7)$ \\
\hline RFR: Anxiety/Depression $(n=26)$ & $4.4( \pm 2.4)$ & $5.1( \pm 2.5)$ & $6.1( \pm 2.5)$ & $7.4( \pm 2.0)$ & $1.3( \pm 1.9)$ & $2.2( \pm 1.7)$ & $2.2( \pm 1.7)$ \\
\hline RFR: General PA $(\mathrm{n}=17)$ & $4.8( \pm 3.1)$ & $5.0( \pm 1.4)$ & $6.2( \pm 2.6)$ & $7.3( \pm 2.0)$ & $1.1( \pm 1.8)$ & $3.1( \pm 2.0)$ & $1.7( \pm 1.6)$ \\
\hline RFR: Other RFR $(n=23)$ & $4.5( \pm 2.2)$ & $4.7( \pm 2.2)$ & $5.5( \pm 2.5)$ & $7.3( \pm 1.4)$ & $1.1( \pm 1.7)$ & $2.9( \pm 2.8)$ & $2.3( \pm 2.6)$ \\
\hline RFR: Unspecified RFR ( $\mathrm{n}=28)$ & $4.1( \pm 2.3)$ & $4.8( \pm 2.3)$ & $5.3( \pm 2.4)$ & $7.6( \pm 2.3)$ & $1.6( \pm 1.9)$ & $3.9( \pm 2.7)$ & $2.0( \pm 1.9)$ \\
\hline SOC: Pre-preparation $(n=23)$ & $4.4( \pm 2.3)$ & $5.5( \pm 1.7)$ & $5.8( \pm 2.5)$ & $8.0( \pm 1.2)$ & $1.3( \pm 1.3)$ & $4.3( \pm 2.5)$ & $2.3( \pm 1.7)$ \\
\hline SOC: Preparation $(n=62)$ & $4.4( \pm 2.5)$ & $4.9( \pm 2.3)$ & $5.7( \pm 2.5)$ & $7.5( \pm 1.9)$ & $1.3( \pm 1.8)$ & $2.8( \pm 2.4)$ & $1.9( \pm 1.9)$ \\
\hline SOC: Action $(n=12)$ & $4.9( \pm 3.1)$ & $4.1( \pm 2.2)$ & $5.7( \pm 2.7)$ & $6.3( \pm 2.3)$ & $0.8( \pm 2.0)$ & $1.4( \pm 2.1)$ & $1.4( \pm 1.7)$ \\
\hline SOC: Maintenance $(n=14)$ & $3.9( \pm 2.1)$ & $4.2( \pm 2.4)$ & $5.2( \pm 2.9)$ & $6.1( \pm 2.7)$ & $1.4( \pm 2.1)$ & $3.0( \pm 2.3)$ & $2.6( \pm 2.1)$ \\
\hline
\end{tabular}

RFR $=$ reason for referral, $\mathrm{SOC}=$ stage of change for physical activity, Pre-preparation $=$ combined category including precontemplators and contemplators 


\section{CHAPTER IV: DISCUSSION}

The purpose of this study was to examine barriers to PA in college students referred to an EIMOC program at a Midwestern university. Barriers were examined in the group of students as a whole (ALL participants), and also when the students were categorized by RFR, gender identity, and SOC for PA. We hypothesized that individuals from different gender identity, SOC and RFR groups would identify different significant barriers for PA. Our hypothesis was not correct, in that groups did not differ in the barriers that they identified as significant.

Lack of Willpower was a highly rated barrier across ALL, which is consistent with some of the previous studies on university students $(2,19)$. However, other studies did not find Lack of Willpower to be the most highly rated barrier, or even one of the most highly rated barriers, in this population (11). In the present study, Lack of Willpower was also a significant barrier for groups of participants based on RFR, gender identity and SOC. On the Barriers to Being Active Quiz, Lack of Willpower is assessed through statements such as "I've been thinking about getting more exercise, but I just can't seem to get started.", "It's easier for me to find excuses not to exercise than to go out to do something.", and "I want to get more exercise, but I just can't seem to make myself stick to anything." In the present study, this common barrier to PA did not differ significantly across the groups when assessed using MANOVA. However, a follow-up ANOVA found with that those in the Pre-preparation stage scored higher on Lack of Willpower relative to those at Action or Maintenance. Similarly, Sevil et al. (32) and Herazo-Beltran et al. (15) found that university students and adults aged 18-69 years, respectively, who were not currently meeting PA guidelines scored higher on all barriers than those who were meeting PA guidelines. Daley and Duda also suggested that college students in the early stages of change 
were less motivated for PA than those in Action and Maintenance (10). Based on the results of the present study, strategies for increasing motivation for PA would likely be beneficial for the group of participants as a whole, and particularly for those in the early stages of change.

Lack of Energy was also a highly rated barrier for ALL, as well as when participants were grouped by RFR, gender identity, and SOC, although no differences were found among groups. The Lack of Energy barrier is assessed through statements such as "I'm just too tired after work to get any exercise.", "I don't get enough sleep as it is. I just couldn't get up early or stay up late to get some exercise.", and "I'm too tired during the week and I need the weekend to catch up on my rest.". Both Daskapan et al. (11) and Ramirez-Velez et al. (28) indicated that Lack of Energy was a significant barrier in their studies on university students, but not one of the most highly rated barriers, as in the present study. In the Daskapan et al. (11) study, the Lack of Energy mean score was 5.9, which is higher than the mean of 5.6 for ALL in the present study. However, both Lack of Support and Lack of Time had higher mean values than Lack of Energy in the Daskapan et al. study (11). Similar to Lack of Willpower, strategies for increasing energy for PA would likely be beneficial for this group of participants.

The statements that assess Lack of Skill include "I don't get enough exercise because I have never learned the skills for any sport.", "I really can’t see learning a new sport at my age.", and "I'm not good enough at any physical activity to make it fun.". Lack of Skill was not one of the more highly rated barriers in the present study (no mean values > 5), either for ALL or when participants were grouped. However, ANOVA comparing groups indicated that those individuals in the SOC of Preparation (4.3) scored higher on this barrier than those in the SOC of Action (1.4), Similarly, Herazo-Beltran et al. (13) found Lack of Skill to be a more highly scored 
barrier in individuals not complying with PA recommendations compared to those who were. An additional result found by the ANOVA was that those identifying as male (3.9) scored the barrier of Lack of Skill more highly than those identifying as female (2.7). Previous research comparing adolescent $(23,30)$ and college-aged (28) male and female subjects found that females rated perceived barriers to PA higher than males, and suggested that this is due to males receiving more exposure to PA than females. In general, and also specifically with regard to Lack of Skill, our results are not consistent with this previous research comparing males and females. While not significantly different, males had higher mean values than females for Social Influence, Lack of Willpower, Fear of Injury, and Lack of Resources, as well as Lack of Skill, where ANOVA revealed a significant difference between the genders. Given the limited subject numbers, particularly for those identifying as male, this must be interpreted with caution.

The other barriers examined in this study by the "Barriers to Being Active quiz" were Lack of Time, Social Influence, Lack of Resources, and Fear of Injury. Of these, Fear of Injury and Lack of Resources both had relatively low mean values for ALL and for groups. However, the means for both Social Influence and Lack of Time approached a 5, and exceeded a five in some cases, although no significant differences were noted when groups were compared. Social Influence is assessed by statements such as "None of my family members or friends like to do anything active, so I don't have a chance to exercise.", "I'm embarrassed about how I will look when I exercise with others.", and "My usual social activities with family or friends do not include physical activity.”. Although not significantly different among SOC groups, there was a trend for participants who reported being in the Pre-preparation (5.5) and Preparation (4.9) stages to report higher scores for Social Influence than those who were in the Action (4.1) and 
Maintenance (4.2) stages. These data suggest that individuals who are "more ready" for PA view Social Influence as less of a barrier to being or continuing to be physically active, and may not perceive peer or family sanction of PA to be as important as those in earlier stages of readiness. Earlier studies found that those not meeting PA recommendations score more highly on all barriers compared to those who are meeting PA recommendations $(13,32)$, and that barriers to PA decrease as individuals move throughout the stages of change (1). The results of the present study would seem to agree with previous research suggesting that individuals who are not currently active and in early stages of change for PA rate all barriers more highly than those who are already active. As such, this group of individuals would benefit from strategies to reduce all types of barriers to promote adoption of a physically active lifestyle. Means for the Lack of Time barrier also approached a 5, and although not significantly, were lower across the board than Lack of Willpower, Lack of Energy, and Social Influence. This result was surprising from University students, as time management can be a challenge in this population $(5,22,35)$, and because previous research has shown Lack of Time to be a meaningful barrier for this population $(11,12,32)$. This barrier is assessed from statements such as “My day is so busy now, I just don't think I can make the time to include PA in my regular schedule.", "Physical activity takes too much time away from other commitments - time, work, family, etc.", and "My free times during the day are too short to include exercise.". Lack of Time is considered an "external barrier", as are Social Influence and Lack of Resources. An external barrier can be characterized as an environmental battle surrounding the client that is less in the participants control (32). An internal barrier can be characterized as a mental or emotional battle between oneself that is more in the participants control to overcome such as Lack of Willpower or Lack of Energy. An 
interesting finding, and one that conflicts with previous research, is that the participants in the present study reported that their significant barriers were "internal" as opposed to "external" barriers. Both Daskapan et al. (11) and Gomez-Lopez et al. (12) found the opposite - that perceived external barriers seemed to have more importance than internal barriers in apparently healthy university students. Similarly, previous research in adults with diabetes (17) indicated that external barriers were more significant than internal barriers. On the other hand, obese adults (15) and adults with anxiety disorders (25) indicated that internal barriers such as "exercise is hard work for me" or "lack of willpower" were more important than external barriers. This previous research formed the basis of our hypothesis that the RFR groups in the present study might differ in their identified significant barriers. Although we did not find group differences, the results on barriers from our RFR groups of "obesity" and "anxiety/depression" did identify internal barriers as more significant than external, as in the Joseph et al. (15) and Pelletier et al. (25) studies with individuals with the same diagnoses. We did not have adequate numbers for a separate RFR group of "diabetes", so we cannot make direct comparisons with other groups or with the previous research by Kennedy et al. at this time (17). Continued data collection and further research from the ongoing EIMOC program examined in this study and at other universities will provide additional data on all RFR groups, which include not only those listed above, but also hypertension, eating disorders, and elevated cholesterol, among others. Identification of barriers in these populations, for whom exercise is medicine, will provide useful information to enable adoption of and adherence to PA. The present results seem to represent a departure from the results of previous research, specifically with regard to which barriers were the most significant, as well as the importance of internal vs. external barriers. The more internal 
the more significant, as well as the importance of internal vs. external barriers. The internal barriers of Lack of Willpower and Lack of Energy were the most highly scored barriers in this group, whereas in previous studies, external barriers such as Lack of Time were scored most highly. A unique aspect of the college students in the present study is that they visited a health professional and were subsequently referred or "prescribed" to a PA program, either as "medicine" for an existing medical condition or as prevention. Additionally, these students showed up for a follow-up intake session. As with PA, Lack of Time has been shown to be a barrier to physician visits (8), so perhaps the participants in the present study have particular views on time or time management skills that result in time being less of a barrier to activities in general when compared to the typical college student. Alternatively, perhaps this population of students have characteristics that make internal barriers seem more difficult to overcome, and therefore, more significant. Another possible difference in the participants in this study is the potential motivator of health. In a meta-analysis of PA behaviors in traditionally-aged college students, Keating et al. (16) notes that health is not a primary motivator for this population. Although motivation was not examined in the present study, it could be speculated that the referral from a health professional to a PA program might put health higher on the list of PA motivators for these college students than for others, creating a unique study population. Health has been shown to be a poor motivator for PA and in a population that is not typically motivated by health (32), perhaps there is cognitive dissonance that results in low motivation and energy as barriers to PA over external barriers. The interaction between motivators for participating in a PA program and barriers in university students referred to a PA program would be an interesting area for future research. 


\section{Strategies for overcoming barriers}

When it comes to addressing barriers, especially those that were rated to be the most meaningful to our subjects, the strategies to conquer each barrier may vary on a case by case basis. The CDC provides a list of strategies for addressing barriers to PA examined using the "Barriers to Being Active Quiz". The list contains numerous ways to overcome each individual barrier examined in this study. For Social Influence, the CDC suggests inviting friends and family members to join in the exercise and plan social activities involving exercise. Lack of Willpower could be addressed by planning ahead and organizing activities and exercise that are enjoyable in order to increase initial and long-term arousal levels. Other techniques could include regular communication from a trainer by text, call, and email in order to increase accountability and lend some extra motivation. Stimulus control may also be an important persuader in the Lack of Willpower. For example, students should try to spend time away from their homes to promote more PA during the day and can increase motivation by exercising with a friend or joining an exercise group or class. When addressing the Lack of Energy barrier, the CDC advises constant reminders and education on a healthy, balanced diet combined with a proper sleep schedule to allow for higher energy levels. The CDC also suggests scheduling PA for times in the day or week when the individual feels most energetic. Stress control may also contribute positively to Lack of Energy, especially in college age students who have stress surrounding schoolwork, a part time job, or outside factors such as social and emotional stress that can be brought upon from everyday life. 


\section{Study Limitations}

The study was limited by subject numbers overall, but particularly for males and RFR groups. Additionally, these participants identified as only male or female, with no other gender identities represented. The present study could also have benefitted from a direct comparison with non-referred students at the university. It should also be noted that the study population was from a single university and a single EIMOC program. One additional limitation could be that these data were self-reported. Barrier information was derived from a questionnaire filled out by each client, which might have resulted in user error if the client was not paying close attention when completing it.

\section{Summary}

While additional research is needed across all campuses in order to truly understand PA barriers in student populations, the results of the present study indicate that university students referred to a PA program were found to have more "internal" barriers rather than "external" barriers - specifically Lack of Willpower, Lack of Energy, and Social Influence being the largest obstacles to overcome as opposed to the external barrier of Lack of Time. This study did not find significant differences between groups with regard to barriers to PA. Each individual will demonstrate unique barriers to PA, or a combination of barriers of PA. Thus, exercise programming should occur in a way that best suits individual needs and helps to address individual barriers. For an individual referred to a program like EIMOC, overcoming barriers to PA may be more realistic and feasible with the help of an educated exercise professional. This is a primary benefit of exercise referrals programs like EIM and EIMOC. Physicians and other health practitioners, who are not trained to provide exercise programming, can refer to exercise 
professionals, who can facilitate not only PA, but also PA barrier reduction. Knowledgeable exercise professionals can assist in addressing barriers through flexibility in scheduling, maximizing exercise time during sessions, creating an encouraging and welcoming social environment, daily/weekly check-ins with clients, providing knowledge and safety on exercise and exercise equipment, and providing resources not available to individuals performing self-led PA. 


\section{REFERENCES}

1. Abarca-Sos, A., Bois, JE., Generelo, E., Julian, JA., Zaragoza, J. Application of Stages of Change Model to Adolescents' Physical Activity in Relation to Psychological Variables. J Sport Med Phy Fitness. 2015;55(11):1397-1406.

2. Al-Otaibi, H. Measuring Stages of Change, Perceived Barriers and Self Efficacy for Physical Activity in Saudi Arabia. Asian Pacific J Canc Prev. 2013;14(2):1009-1016.

3. American College of Sports Medicine. Exercise is Medicine [Internet]. [Cited 2021 Mar 27]. Available from http://www.exerciseismedicine.org/support_page.php/about-eim/.

4. Balducci, S., Sacchetti, M., Haxhi, J., et al. Physical Exercise as Therapy for Type 2 Diabetes Mellitus. Diabetes Retab Res Rev. 2014;30(1):13-23.

5. Britton, B., Tesser, A. Effects of time-management practices on college grades. $J$ Educ Psych. 1991;83(3):405-410.

6. Brown, C., Perrin, E. Obesity Prevention and Treatment in Primary Care. Academic Pediatrics, U.S. National Library of Medicine. 2018;18(7):736-774.

7. Brown, S. Measuring Perceived Benefits and Perceived Barriers for Physical Activity. Am J Health Behav, 2005; 29(2):107-116.

8. Byrne, S., Taber, J., Persoskie, A. Why Do People Avoid Medical Care? A Qualitative Study Using National Data. J Gen Intern Med. 2015;30:290-297.

9. Cocca, A., Liukkonen, J., Mayor, D. Health related physical activity levels in youth and young adults. Percept Mot Skills. 2014;118:4-14.

10. Daley, A., Duda, J. Self-Determination, Stage of Readiness to Change for Exercise, and Frequency of Physical Activity in Young People. Eur J Sport Sci 2006;6(4):231-243. 
11. Daskapan, A., Tuzun, E., Eker, L. Perceived Barriers to Physical Activity In University Students. J Sport Sci Med. 2016;5(4):615 - 620.

12. Gómez-López, M., Gallegos A., Exteremera, A. Perceived Barriers by University Students in the Practice of Physical Activities. J Sport Sci Med, 2010; 9(3):374-381.

13. Herazo-Beltrán, Y., Pinillos, Y., Vidarte, J., Crissien, E., Suarez, D., Garcia, R. Predictors of Perceived Barriers to Physical Activity in the General Adult Population: A Cross-Sectional Study. Brazilian J Phys Ther. 2017;21(1):44-50.

14. Heridi, A., Stevens, R. Transition to university and vigorous physical activity: implications for health and psychological well-being. J Am Coll Health, 2004;52(4):181188.

15. Joseph, P., Bonsignore, A., Kunkel, G., Grace, S., Sockalingam, S., Oh, P. Benefits and Barriers to Exercise among Individuals with Class III Obesity. Am J Health Behav, 2019; 43(6):1136-1147.

16. Keating, X., Guan, J., Piñero J. A Meta-Analysis of College Students' Physical Activity Behaviors. J Am Coll Health: 2015;54(2):116-125.

17. Kennedy, A., Narendran, P., Andrews, R., Daley, A., Greenfield, S. Attitudes and Barriers to Exercise in Adults with a Recent Diagnosis of Type 1 Diabetes: A Qualitative Study of Participants in the Exercise for Type 1 Diabetes (EXTOD) Study. BMJ Open. 2018;8(1):e017813.

18. Kessler, R., P. Berglund, Ghrouz, A. et al. Physical Activity and Sleep Quality in Relation to Mental Health among College Students. Sleep Breath. 2019;23(2):627-634. 
19. Kulavic K., Hultquist C., McLester, J. A Comparison of Motivational Factors and Barriers to Physical Activity among Traditional versus Nontraditional College Students. $J$ Am Coll Health. 2013;61(2):60-66.

20. Liu, M., Ge, Y., Xin, S., et al. Association of Physical Activity, Sedentary Time, and Sleep Duration on the Health-Related Quality of Life of College Students in Northeast China. Health Qual Life Outcomes. 2019;17(1):124.

21. Liu, X., Ping, S., Wenjuan, G. Changes in Undergraduate Students' Psychological WellBeing as They Experience University Life. Int J Environ Res Public Health. 2019:16(16):2864 .

22. Macan, T., Shahani, C., Dipboye, R., Phillips, A. College students' time management: Correlations with academic performance and stress. J Educ Psych. 1990;82(4),760-768.

23. Martínez-Lemos, R., Puig-Ribera, A., Garcia-Garcia, O. Perceived Barriers to Physical Activity and Related Factors in Spanish University Students. Open J Prev Med. 2014;4(4):1.

24. Nijs, J., Daenen, L., Varkey, E. Exercise, Not to Exercise, or How to Exercise in Patients with Chronic Pain: Applying Science to practice. Clin J Pain., 2015;31(2):108-114.

25. Pelletier, L., Shanmugasegaram, S., Patten, S., Demers, A. Self-Management of Mood and/or Anxiety Disorders through Physical Activity/Exercise. Health Prom Chro Dis Prev Can. 2017;37(5):149-159.

26. Peterson, N., Sirard, J., Kulbok, P., DeBoer, M., Erickson, J. Sedentary Behavior and Physical Activity of Young Adult University Students. Res Nursing Health, 2018;41(1):30-38. 
27. Prochaska, J., DiClemente, C. Stages and processes of self-change of smoking: toward an integrative model of change. J Consulting Clinical Psychol. 1983;51(3):390-5.

28. Ramírez-Vélez, R., Tordecilla-Sanders, A., Laverde, D., et al. The Prevalence of Barriers for Colombian College Students Engaging in Physical Activity. Nutricion Hospitalaria. 2014;31(2):858-865.

29. Romero-Blanco, C., Rodriguez-Almagro, J., Onieva-Zafra, M., Parra-Fernandez, M., Prado-Laguna, M., Hernandez-Martinez, A. Physical Activity and Sedentary Lifestyle in University Students: Changes during Confinement Due to the COVID-19 Pandemic. Int J Environ Res Public Health. 2020;17(18):6567.

30. Rosselli, M., Ermini E., Tosi, B., et al. Gender Differences in Barriers to Physical Activity among Adolescents. Nut Metab Cardio Dis. 2020;30(9):1582-1589.

31. Sallis, R., Coleman, K., Ngor, E., et al. Self-Reported Exercise in Patients Using an Exercise Vital Sign. Med Sci Sports Exerc. 2011;43(1):547.

32. Sevil, J., Praxedes, A., Abarca-Sos, A., Del Villar, F., Garcia-Gonzalez, L. Levels of Physical Activity, Motivation and Barriers to Participation in University Students. $J$ Sports Med Phys Fit. 2016;56(10):1239-1248.

33. Sharman, J., La Gerche, A., Coombes, J. Exercise and Cardiovascular Risk in Patients With Hypertension. Am J Hypertens. 2015;28(2):147-158.

34. Snedden, T., Scerpella, J., Kliethermes, S., et al. Sport and Physical Activity Level Impacts Health-Related Quality of Life Among Collegiate Students. Am J Health Prom. 2019;33(5):675-682. 
35. Trueman, M., Hartley, J. A comparison between the time-management skills and academic performance of mature and traditional-entry university students. High Educ. 1996;32:199-215.

36. Varela-Mato, V., Molina, A., Cancela, J., Ayan, C. Lifestyle and health among university students: differences in gender and academic diagnosis. Int J Environ Res Pub Health. 2013;10:2728-2776.

37. Zalewski, K., Alt, C., Arviene-Barrow, M. Identifying Barriers to Remaining Physically Active After Rehabilitation: Differences in Perception Between Physical Therapists and Older Adult Patients. J Ortho Sports Phys Ther. 2014;44(6):415-424. 